\title{
Members Build Bluebird Houses
}

By Frank Roy, President, Saskatoon Natural History Society

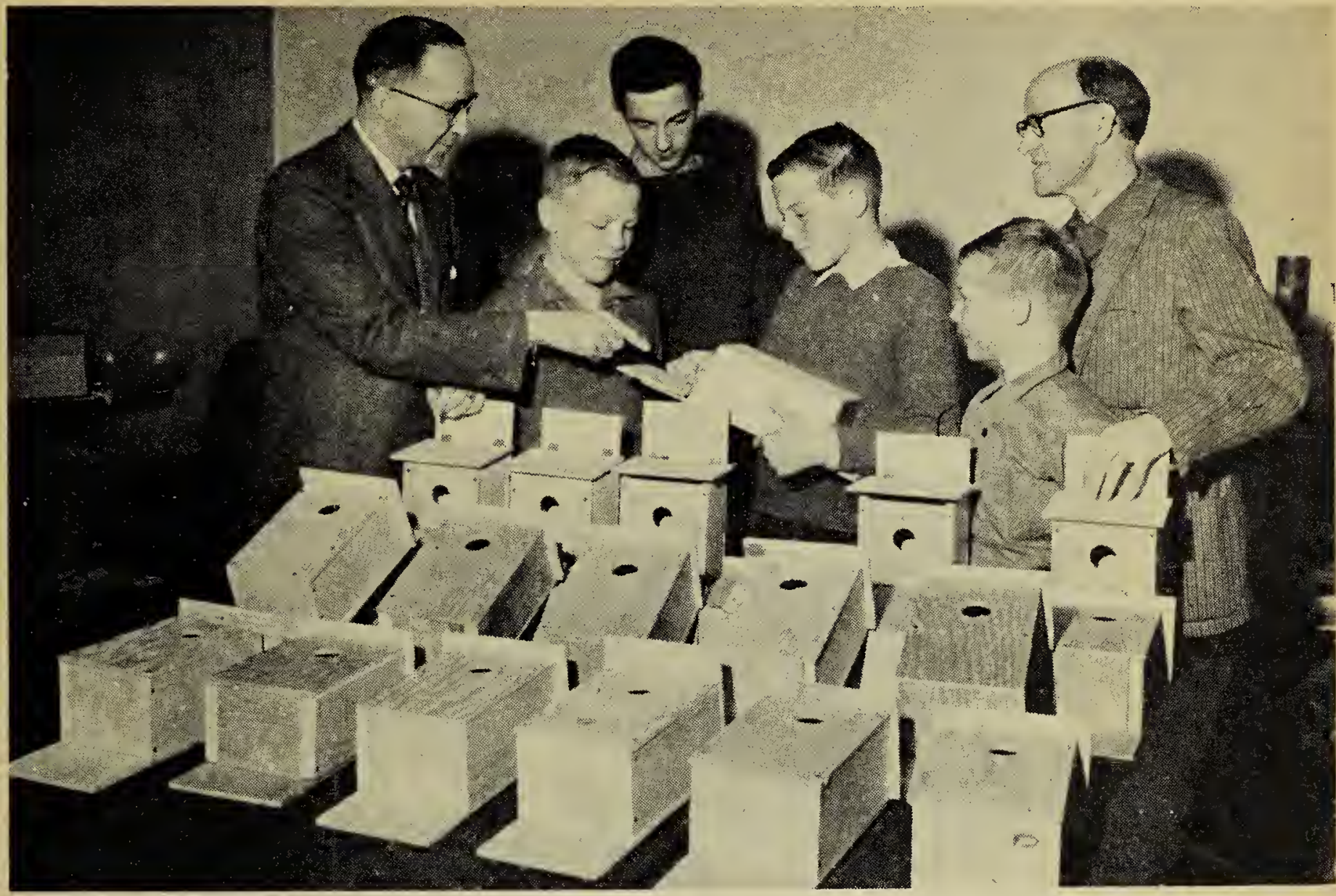

In recent years the Eastern Bluebird has decreased so rapidly in numbers that fears have been expressed for its continued survival. The rapid decline has been attributed to three factors: indiscriminate mass insect spraying, icy winter temperatures and late spring snowstorms, and, most important, lack of nesting places. Starlings and House Sparrows now occupy thousands of nestholes formerly available to Bluebirds.

Encouraged by results of birdhouse campaigns in several Eastern states and provinces, members of the Saskatoon Natural History Society voted at the March meeting to experiment with Bluebird houses in the Saskatoon area to encourage Mountain Bluebirds. While we had no certain evidence that Mountain Bluebirds were declining in numbers or that they were short of nesting sites, everyone agreed that putting up nest-boxes might well encourage more Bluebirds to remain, as well as enticing such species as Tree Swallows and Downy Woodpeckers.

Bert Hardy and Jim Slimmon rounded up the necessary lumber; Greg Michalenko offered the use of power tools; Stuart Houston provided the specifications and his son, Stan- ley, constructed a model house. The actual builders were Jim Slimmon, Colin Ward, Stuart Houston, Russ Shemko, Bill Richards, Dr. Michalenko, Greg Michalenko, and Jonathan, Peter and Christopher Gerrard. Art Heron contributed money for hinges and screws. In a couple of days 37 nest-boxes were built.

To date members of the Society have put up over 30 boxes in the area south and west of Saskatoon. A careful record of locations is kept. The houses are set on posts, generally in the open, about four feet from the ground, and at least a quarter of a mile from the nearest roads and buildings. Where possible, owners of the land have been contacted. In nearly every instance, farmers have been pleased to-co-operate with us in this project.

At the time of writing, it seems unlikely that many boxes will be occupied this year. In the course of the next couple of seasons we may be able to draw some conclusions re size of nest-box, diameter of hole (at present $1 \frac{1}{2}$ inches in order to keep out Starlings), location in relation to trees, and height from the ground. In a later article we shall indicate the results of the Bluebird experiment. 